\title{
Does cemented or cementless single-stage exchange arthroplasty of chronic periprosthetic hip infections provide similar infection rates to a two-stage? A systematic review
}

\author{
D. A. George ${ }^{1 *}$, N. Logoluso2 , G. Castellini ${ }^{3,4}$, S. Gianola ${ }^{4,5}$, S. Scarponi ${ }^{2}$, F. S. Haddad', L. Drago ${ }^{4,6}$ and C. L. Romano ${ }^{2}$
}

\begin{abstract}
Background: The best surgical modality for treating chronic periprosthetic hip infections remains controversial, with a lack of randomised controlled studies. The aim of this systematic review is to compare the infection recurrence rate after a single-stage versus a two-stage exchange arthroplasty, and the rate of cemented versus cementless single-stage exchange arthroplasty for chronic periprosthetic hip infections.
\end{abstract}

Methods: We searched for eligible studies published up to December 2015. Full text or abstract in English were reviewed. We included studies reporting the infection recurrence rate as the outcome of interest following singleor two-stage exchange arthroplasty, or both, with a minimum follow-up of 12 months. Two reviewers independently abstracted data and appraised quality assessment.

Results: After study selection, 90 observational studies were included. The majority of studies were focused on a twostage hip exchange arthroplasty (65\%), $18 \%$ on a single-stage exchange, and only a $17 \%$ were comparative studies. There was no statistically significant difference between a single-stage versus a two-stage exchange in terms of recurrence of infection in controlled studies (pooled odds ratio of 1.37 [95 \% Cl=0.68-2.74, $\left.\left.\right|^{2}=45.5 \%\right]$ ). Similarly, the recurrence infection rate in cementless versus cemented single-stage hip exchanges failed to demonstrate a significant difference, due to the substantial heterogeneity among the studies.

Conclusion: Despite the methodological limitations and the heterogeneity between single cohorts studies, if we considered only the available controlled studies no superiority was demonstrated between a single- and twostage exchange at a minimum of 12 months follow-up. The overalapping of confidence intervals related to single-stage cementless and cemented hip exchanges, showed no superiority of either technique.

Keywords: Infection, Periprosthetic hip infections, Exchange arthroplasty, Single-stage, Two-stage, Cemented, Cementless

\footnotetext{
* Correspondence: davidgeorge@doctors.org.uk

${ }^{1}$ Department of Trauma and Orthopaedic Surgery, University College London

Hospitals, London, UK

Full list of author information is available at the end of the article
} 


\section{Background}

There remains an ongoing discrepancy in the literature between the infection recurrence rates after a single-stage exchange arthroplasty compared to a two-stage exchange for chronic periprosthetic hip infections. Infection has been reported as the third reason for revision after total hip arthroplasty in the USA [1], complicating 0.5 to $2 \%$ of primary arthroplasties [2-4].

The operative approach is determined by a combination of surgeon, patient, joint, and infection factors. Literature regarding the optimal inclusion and exclusion criteria for each modality is varied, but there is a general consensus that a two-stage exchange should be undertaken in patients with unknown pathogens or those of highvirulence [5-7].

Previous attempts at addressing this issue have been undertaken by various prospective [8-10] and retrospective cohort studies [11-13] comparing the modalities used, or systematic reviews $[14,15]$, but due to various limitations, such as determining the ideal candidate' for each treatment, a definitive conclusion has not been shown.

In the lack of large prospective, randomised controlled comparative trials, this comprehensive systematic review and meta-analysis of observational studies was undertaken to investigate the relative efficacy, in terms of recurrence of the infection, in a single- compared to two-stage exchange arthroplasty for chronic periprosthetic hip infection. A similar review has been recently reported for periprosthetic knee and shoulder infections [16, 17]. In addition, we aim to further analyse the infection rates after cemented and cementless single-stage exchanges, which have not been previously undertaken.

\section{Methods}

\section{Search startegy}

We searched for studies published up to December 2015 on the following databases: EMBASE; PubMed/Medline; Medline Daily Update; Medline In-Process and other nonindexed citations; Google Scholar; SCOPUS; CINAHL; Cochrane Central Register of Controlled Trials and Cochrane Database of Systematic Reviews; NHS Health Technology Assessment; http://www.google.com; and http://www.yahoo.com. The search was executed using $\mathrm{MeSH}$ and text keywords [see Appendix 1] and adapted for each database in order to achieve more sensitivity. Original study reports as well as review articles were retrieved, and the reference lists from all reviewed articles were assessed to complete the literature search. No language restrictions were applied.

\section{Eligibility criteria}

We included studies that fuflilled the following inclusion criteria: (a) sample of at least 4 patients with prosthetic hip infection that underwent a surgical revision; (b) single-stage or two-stage exchange arthroplasty as surgical treatment; (c) a minimum follow-up of 12 months; (d) study reporting results relating to delayed or chronic infection (6 weeks or later) stages of disease; (e) recurrent infection after treatment as outcome; (f) study design classifiable as comparative study, prospective or retrospective study with no compared group.

\section{Study selection}

Two investigators independently searched and reviewed the literature and classified the references in terms of whether they should be included on the basis of the title and abstract. In order to include all studies, if full text was not avaiable, abstracts with enough information to be qualitative and quantitative assessed were included. If more than one paper by the same author(s) was retrieved and their follow-ups were found to overlap, only the most recent reference with the longest follow-up and largest patient series was included. Discrepancies were solved by consusus.

\section{Data extraction}

Data collection was performed by four reviewers. The following data were extracted: name of author, year of publication, type of study design, minimum, maximum and mean period of follow up, number of patients included and number of recurrent infections (in case of comparative studies number of patients per group).

\section{Outcome}

Our primary outcome was the recurrent infection rate. We chose to extract data only of patients who completed the single-stage or the two-stage revision. We did not include patients that had received a supplemental revision for a new infection following the prior septic revision, nor those who did not receive the complete reimplantation process, or died for cause unrelated to infection recurrence.

\section{Quality assessment}

In order to reflect the information expected to be present in each included study, as a measure of quality we selected and evaluated the following two bias: (1) retrospective or prospective analysis and source of data (record bias); (2) relevance and definition of measured outcome for infection (reporting bias). Two independent reviewers performed the quality assessment; disagreements were resolved by consensus.

\section{Statistical analysis}

Infection recurrence rates were treated as dichotomous variables using the odds ratio (OR) for meta-analysis of controlled studies (single-stage versus two-stage) and 
the ratio between number of infection and total number of patients for proportional meta-analysis of cohort studies reporting only one treatment group, along with $95 \%$ confidential intervals $(\mathrm{CI})$.

The analysis was performed using extracted patient data from the individual studies. Because of the differences among the included studies and several uncontrolled variables, we used a random-effect model [18]. The results from individual trials were combined when possible, but otherwise single forest plots will be reported without the overall duration of follow-up.

In single forest plot, each horizontal line on the graph represents a case series included in the meta-analysis. The estimated effect is marked with a solid black square, and the size of the square represents the weight of the corresponding study plotted in the meta-analysis. The combined total estimate is marked with an unfilled diamond at the bottom of the forest plot. Statistical heterogeneity was assessed using the $\mathrm{I}^{2}$ statistic and assume influential when the $\mathrm{I}^{2}$ was greater than $50 \%$ and $p<0.05$ as statistically significant for the calculation of heterogeneity; $\mathrm{I}^{2}$ illustrates the percentage of the variability in effect estimates resulting from clinical and/or methodological heterogeneity rather than sampling error $[19,20]$.
Forest plots were presented for the following interventions: single-stage, two-stage, single-stage cemented, and single-stage cementless hip arthroplasties. The presence of an overlap of the confidence intervals from the two interventions, for example between single-stage and two stage exchanges, suggests similar effect of the interventions on the outcome. Alternatively, non-overlapping CIs suggest different effects from the interventions studied [21].

We used the following software: StatsDirect [StatsDirect Ltd, Cheshire, UK] for the proportional meta-analyses and Review Manager [RevMan version 5.2, The Cochrane Collaboration, The Nordic Cochrane Centre, Copenhagen 2012] for meta-analyses in controlled studies.

\section{Results}

Selection and characteristics of studies

The results of the study selection are shown in Fig. 1. We found 90 original observational studies. Sixteen studies reported the results only after a single-stage exchange, 59 reported only a two-stage hip exchange and 15 reported the comparison of a single-stage versus a two-stage. Overall, 31 original studies reported data about single-stage hip exchange arthroplasty (number of patients, $n=1608$ ), which included 27 full text and 4

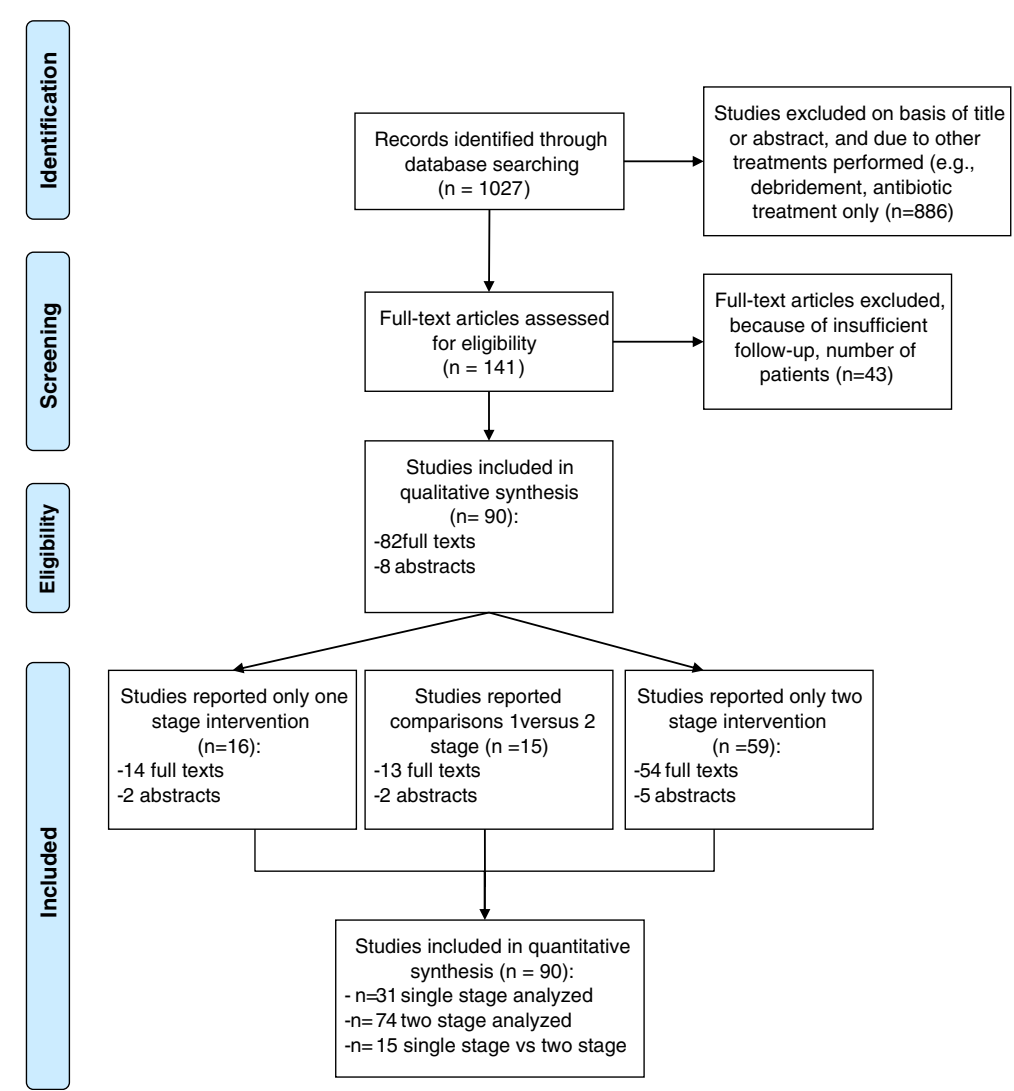

Fig. 1 Flow diagram of study selection process 
Table 1 General characteristics, record bias and reporting bias of included studies

\begin{tabular}{|c|c|c|c|c|c|c|c|c|c|c|}
\hline \multirow[t]{2}{*}{ Study First Author } & \multirow[t]{2}{*}{ Ref. } & \multirow[t]{2}{*}{ Year } & \multirow{2}{*}{$\begin{array}{l}\text { Patients } \\
\text { (n) }\end{array}$} & \multirow{2}{*}{$\begin{array}{l}\text { Stage } \\
\text { Investigated }\end{array}$} & \multicolumn{3}{|c|}{ Follow Up (months) } & \multirow[t]{2}{*}{ Design } & \multirow{2}{*}{$\begin{array}{l}\text { Record } \\
\text { Bias }\end{array}$} & \multirow[t]{2}{*}{ Reporting Bias (Outcome Measure) } \\
\hline & & & & & $\overline{M i n}$ & Max & Mean & & & \\
\hline Babiak & {$[28]$} & 2012 & 9 & Two & 36 & 180 & 84 & NA & Yes & NA \\
\hline Babis & {$[29]$} & 2015 & 31 & Two & 20 & 48 & 30 & Retrospective & Yes & Symptoms, Imaging, Laboratory \\
\hline Berend & {$[30]$} & 2013 & 186 & Two & 24 & 180 & 53 & Retrospective & NR & Culture \\
\hline Biring & [31] & 2009 & 48 & Two & 120 & 180 & 144 & Retrospective & Yes & Culture \\
\hline Bori & {$[32]$} & 2014 & 24 & Single & 25 & 94 & 45 & Retrospective & Yes & Culture \\
\hline Buchholz & {$[33]$} & 1981 & 583 & Single & 24 & 132 & - & Prospective & Yes & Culture \\
\hline Buttaro & {$[34]$} & 2005 & 29 & Two & 24 & 60 & 32.4 & Retrospective & Yes & Symptoms, Imaging, Laboratory \\
\hline Cabrita & {$[8]$} & 2007 & 38 & Two & 24 & 102 & 48 & Prospective & Yes & Culture \\
\hline Callaghan & {$[35]$} & 1999 & 12 & Single & 12 & 168 & 109.2 & Retrospective & Yes & Imaging \\
\hline Camurcu & {$[36]$} & 2015 & 41 & Two & 24 & 96 & 54 & Retrospective & Yes & Culture \\
\hline Carlsson & {$[37]$} & 1985 & 72 & Both & 12 & 72 & - & Prospective & Yes & Symptoms, Imaging, Culture \\
\hline Chen & {$[38]$} & 2015 & 155 & Two & 36 & 180 & 116.4 & Retrospective & NR & Culture \\
\hline Choi & {$[12]$} & 2013 & 61 & Both & 12 & 132 & 61 & Retrospective & Yes & Culture \\
\hline Colyer & {$[10]$} & 1994 & 37 & Two & 12 & 88 & 36 & Unclear & Yes & Culture \\
\hline Cordero-Ampuero & {$[39]$} & 2009 & 36 & Two & 12 & 144 & 52.8 & Prospective & Yes & Culture \\
\hline D'Angelo & {$[40]$} & 2011 & 28 & Two & 18 & 106 & 53 & Retrospective & Yes & Symptoms, Imaging, Laboratory \\
\hline Darley & [41] & 2009 & 19 & Two & 24 & 36 & 26 & Prospective & Yes & Symptoms, Culture \\
\hline De Man & {$[42]$} & 2011 & 72 & Both & 17 & 204 & 60 & Retrospective & Yes & Culture \\
\hline Degen & {$[43]$} & 2012 & 30 & Two & 24 & 70 & 43 & Retrospective & Yes & Symptoms, Culture \\
\hline Ekpo & {$[44]$} & 2014 & 19 & Two & 24 & 132 & 48 & Retrospective & Yes & Laboratory, Culture \\
\hline Evans & {$[45]$} & 2004 & 23 & Two & 24 & 108 & 48 & Prospective & NR & Symptoms, Culture \\
\hline Fehring & {$[46]$} & 1999 & 25 & Two & 24 & 98 & 41 & Prospective & Yes & Symptoms, Laboratory \\
\hline Fink & {$[47]$} & 2009 & 36 & Two & 24 & 60 & 35 & Prospective & Yes & Culture \\
\hline Fitzgerald & {$[48]$} & 1985 & 131 & Two & 24 & 108 & 49 & Retrospective & Yes & Symptoms \\
\hline Gao & [49] & 2008 & 15 & Both & 12 & 37 & 19 & NA & NA & Culture \\
\hline Garvin & {$[50]$} & 1994 & 40 & Both & 24 & 120 & 60 & NA & NA & Culture \\
\hline Haddad & [51] & 2000 & 50 & Two & 24 & 104 & 69.6 & Retrospective & Yes & Symptoms \\
\hline Hofmann & {$[52]$} & 2005 & 27 & Two & 28 & 148 & 76 & Retrospective & Yes & Symptoms, Imaging, Laboratory \\
\hline Hope & [53] & 1989 & 80 & Both & 2 & 121 & - & Retrospective & Yes & Culture \\
\hline Hsieh & {$[55]$} & 2004 & 128 & Two & 24 & 96 & 58.8 & Retrospective & Yes & Symptoms, Laboratory \\
\hline Hsieh & [11] & 2009 & 99 & Two & 24 & 60 & 43 & Retrospective & Yes & Symptoms, Culture \\
\hline Hsieh & [54] & 2013 & 28 & Two & 48 & 120 & 86 & Retrospective & Yes & Symptoms,Culture, Laboratory \\
\hline Hughes & [24] & 1979 & 26 & Both & 32 & 83 & 51 & Retrospective & Yes & Symptoms, Imaging, Laboratory, Culture \\
\hline Ibrahim & {$[56]$} & 2014 & 125 & Two & 60 & 75 & 103.2 & Retrospective & Yes & Symptoms, Laboratory, Culture \\
\hline Ilchmann & [57] & 2015 & 38 & Single & 24 & 181.2 & 79.2 & Retrospective & Yes & Symptoms, Culture \\
\hline Jenny & [58] & 2014 & 63 & Single & 36 & 72 & - & Retrospective & Yes & Symptoms, Culture \\
\hline Johnson & [59] & 2013 & 66 & Two & 24 & 105 & 45 & Retrospective & Yes & Symptoms, Laboratory, Culture \\
\hline Karpas & {$[60]$} & 2003 & 18 & Two & 24 & 120 & 42 & Retrospective & Yes & NR \\
\hline Kent & [61] & 2010 & 12 & Two & 26 & 60 & 38 & Retrospective & NR & NR \\
\hline Ketterl & [13] & 1988 & 161 & Two & 24 & 168 & 32 & NA & NA & NA \\
\hline Kim & {$[63]$} & 2011 & 130 & Two & 60 & 168 & 124.8 & Retrospective & Yes & Laboratory, Culture \\
\hline Klouche & {$[22]$} & 2012 & 84 & Both & 24 & 68 & 35 & Prospective & Yes & Culture \\
\hline Koo & {$[62]$} & 2001 & 22 & Two & 24 & 78 & 41 & Prospective & Yes & Symptoms, Imaging, Laboratory \\
\hline Lai & {$[64]$} & 1996 & 39 & Two & 30 & 84 & 48 & Prospective & Yes & Symptoms, Laboratory \\
\hline Lee & {$[65]$} & 2013 & 17 & Two & 24 & 96 & 48 & Retrospective & Yes & Symptoms, Laboratory, Culture \\
\hline
\end{tabular}


Table 1 General characteristics, record bias and reporting bias of included studies (Continued)

\begin{tabular}{|c|c|c|c|c|c|c|c|c|c|c|}
\hline Leung & [66] & 2011 & 38 & Two & 24 & 123 & 58 & Retrospective & Yes & Symptoms,Laboratory \\
\hline $\mathrm{Li}$ & [67] & 2015 & 10 & Both & 78 & 187.2 & 103.2 & Retrospective & Yes & Symptoms, Laboratory, Culture \\
\hline Lieberman & {$[68]$} & 1994 & 32 & Two & 24 & 74 & 40 & Retrospective & NR & NR \\
\hline Macheras & [69] & 2012 & 35 & Two & 84 & 168 & 139.2 & Retrospective & Yes & NR \\
\hline Magnan & [70] & 2001 & 8 & Two & 24 & 48 & 35 & Retrospective & NR & NR \\
\hline Masri & [71] & 2007 & 29 & Two & 24 & 88 & 47 & Retrospective & Yes & Symptoms, Laboratory \\
\hline McDonald & [72] & 1989 & 81 & Two & 24 & 163.2 & 66 & Prospective & Yes & Culture \\
\hline McKenna & [73] & 2009 & 30 & Two & 24 & 60 & 35 & Retrospective & Yes & Laboratory \\
\hline Miley & {$[74]$} & 1982 & 46 & Single & 32 & - & 48.5 & Prospective & NR & Unclear \\
\hline Morales & [75] & 1999 & 37 & Two & 36 & 156 & 57.6 & NA & NA & NA \\
\hline Morscher & [76] & 1994 & 74 & Both & 12 & 132 & 84 & NA & Yes & Symptoms, Imaging, Laboratory \\
\hline Mulcahy & [77] & 1996 & 15 & Single & 24 & 84 & 53 & Retrospective & Yes & Symptoms, Imaging, Laboratory, Culture \\
\hline Nestor & [78] & 1994 & 34 & Two & 24 & 72 & 47 & Retrospective & Yes & Culture \\
\hline Neumann & [79] & 2011 & 44 & Two & 36 & 120 & 67 & Retrospective & Yes & Laboratory \\
\hline Nusem & {$[80]$} & 2006 & 18 & Two & 60 & 168 & 108 & Retrospective & Yes & Unclear \\
\hline Oussedik & [9] & 2010 & 50 & Both & 66 & 105.7 & 81.6 & Prospective & Yes & Imaging, Laboratory \\
\hline Pignatti & [81] & 2010 & 41 & Two & 60 & 120 & 63.6 & Retrospective & Yes & Symptoms, Imaging, Laboratory \\
\hline Raut & [82] & 1995 & 57 & Single & 24 & 151 & 88 & Prospective & Yes & Symptoms, Laboratory \\
\hline Romanò & [83] & 2012 & 183 & Two & 24 & 104 & 56 & Retrospective & Yes & Laboratory, Culture \\
\hline Rudelli & [84] & 2008 & 32 & Single & 24 & 96 & 52.8 & Unclear & Yes & Imaging, Laboratory, Culture \\
\hline Sabry & [85] & 2013 & 78 & Two & 24.3 & 135.3 & 58 & Retrospective & Yes & Symptoms, Laboratory \\
\hline Sanchez & [86] & 2009 & 168 & Two & 24 & 192 & 84 & Retrospective & Yes & Symptoms, Culture \\
\hline Sanzen & [87] & 1988 & 102 & Both & 24 & 108 & - & Prospective & Yes & Culture \\
\hline Schneider & [88] & 1989 & 26 & Single & 12 & 108 & - & NA & Yes & NA \\
\hline Schwarzkopf & [89] & 2014 & 56 & Two & 12 & - & 32.4 & Retrospective & Yes & Laboratory, Culture \\
\hline Seung-Jae & [90] & 2009 & 34 & Two & 24 & 120 & 52.8 & Retrospective & Yes & Symptoms, Culture \\
\hline Stockley & [91] & 2008 & 114 & Two & 24 & 175 & 74 & Prospective & Yes & Symptoms, Laboratory, Culture \\
\hline Sudo & {$[25]$} & 2008 & 7 & Two & 27.6 & 73.2 & 60 & Retrospective & Yes & Symptoms, Imaging, Laboratory \\
\hline Takigami & [92] & 2010 & 8 & Two & 24 & 81 & 49 & Retrospective & Yes & Symptoms, Laboratory \\
\hline Thabe & [93] & 2007 & 16 & Two & 72 & 120 & 75.6 & Prospective & Yes & NR \\
\hline Toulson & [94] & 2009 & 82 & Two & 24 & 203 & 64.8 & Retrospective & Yes & Unclear \\
\hline Ure & [95] & 1998 & 20 & Single & 42 & 205.2 & 118.8 & Prospective & Yes & Symptoms, Imaging, Laboratory, Culture \\
\hline van Diemen & [96] & 2013 & 136 & Two & 24 & 180 & 72 & Retrospective & Yes & Symptoms, Imaging, Laboratory, Culture \\
\hline Wang & [97] & 2011 & 12 & Two & 36 & 96 & 64.8 & NA & Yes & NR \\
\hline Weber & [98] & 1986 & 33 & Both & 60 & 96 & 72 & Retrospective & NR & Laboratory \\
\hline Whittaker & [99] & 2009 & 41 & Two & 25 & 83 & 49 & Retrospective & Yes & Culture, Laboratory \\
\hline Wilson & {$[100]$} & 1974 & 19 & Single & 24 & - & - & Prospective & & Culture \\
\hline Wilson & [24] & 1989 & 22 & Both & 36 & 120 & 60.2 & Prospective & Yes & Symptoms, Imaging, Laboratory \\
\hline Winkler & [27] & 2008 & 37 & Single & 63 & 183 & 103 & Prospective & Yes & Symptoms, Imaging, Laboratory \\
\hline Wolf & [101] & 2014 & 92 & Both & 24 & - & - & Retrospective & Yes & Symptoms, Laboratory, Culture \\
\hline Wroblewski & [23] & 1986 & 101 & Single & 38.8 & - & - & Prospective & NR & NR \\
\hline Yamamoto & [102] & 2003 & 17 & Two & 14 & 62 & 38 & Retrospective & Yes & Laboratory \\
\hline Yoo & [103] & 2009 & 12 & Single & 39.6 & 135.6 & 86.4 & Prospective & Yes & Laboratory, Culture \\
\hline Younger & [104] & 1997 & 48 & Two & 24 & 63 & 43 & Prospective & Yes & Culture \\
\hline Zeller & [105] & 2014 & 99 & Single & 24 & - & 41.6 & Prospective & Yes & NA \\
\hline
\end{tabular}


abstracts. Seventyfive studies reported on two-stage exchanges $(n=3679)$, of which 68 were full texts and 7 abstracts. Characteristics of the included studies are summarized in Table 1.

The number of patients undergoing a single-stage exchange ranged from 12 to 583, with a follow-up of 12 to 183 months. Considering a single-stage exchange performed with cementless implants (with or without antibiotic-loaded bone grafts) we found a total of 148 patients (mean follow-up: 78.1 months) whereas for single-stage exchange performed with cemented implant involved 1271 patients (mean follow-up: 78.1 months).
The number of cases for only two-stage exchange studies ranged from 7 to 186, with a follow-up of 12 to 203 months.

\section{Quality assessment}

The quality of included studies is shown in Table 1. Overall, $62 \%$ of included studies were retrospective, $29 \%$ prospective and $8 \%$ were not definable because the full text was unavailable. Observational studies can produce high quality information but, given the nature of these study design, the lack of a control group and the likely confounding variables, the methodological

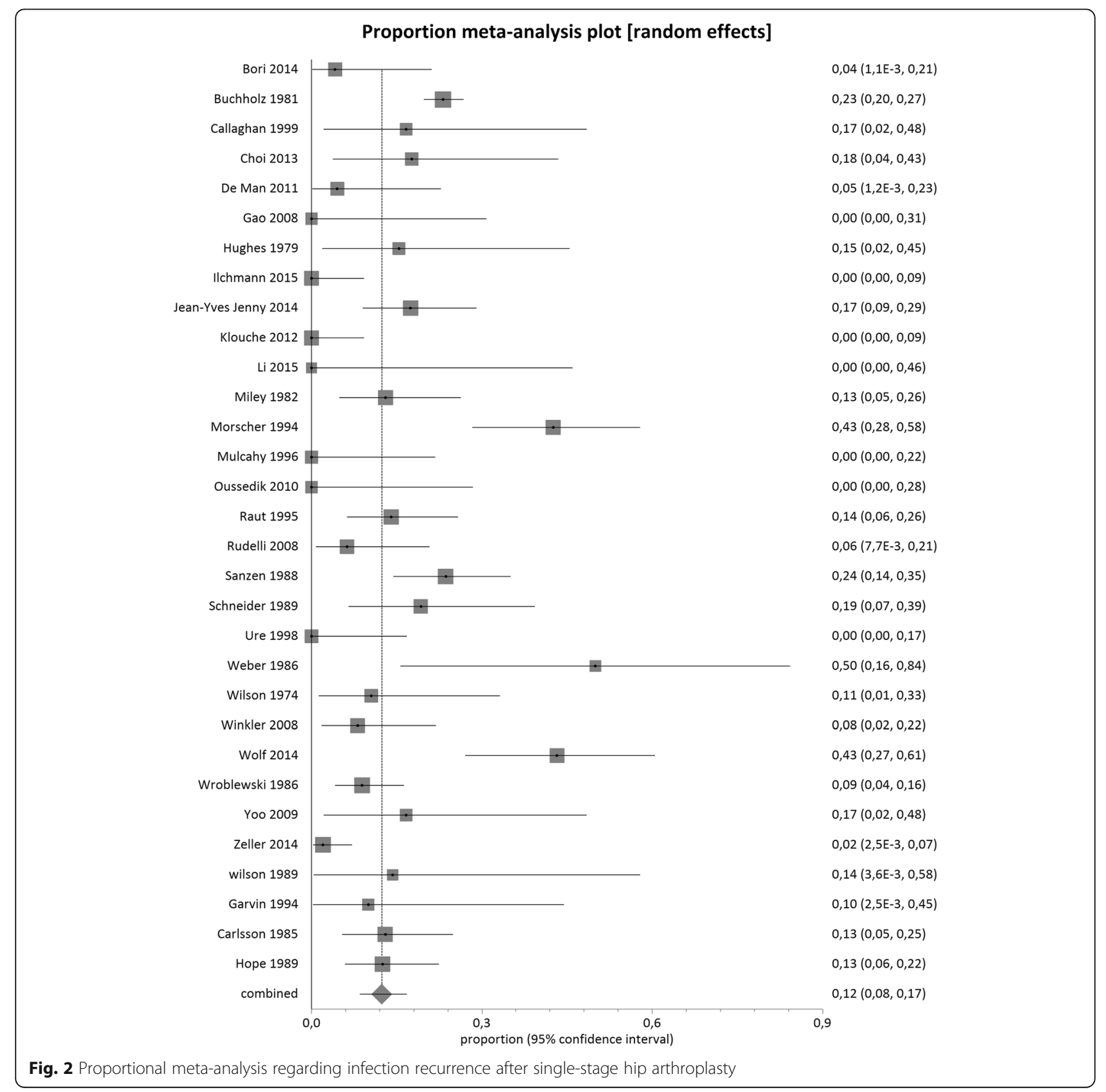


quality was limited leading to difficult generalisation of results. The outcome was specified in the majority of the studies (84\%), selecting infection recurrence as the elective outcome to reflect the success of the two types of interventions. In the half of the included studies, the infection recurrence was diagnosed with more than two measurements (i.e. positive culture, clinical symptoms, imaging etc.). Nevertheless, a unique and universal definition of 'hip periprosthetic infection' was not adopted and among studies.

Concerning data reporting, only $57.3 \%$ of the studies gave a description of their criteria for selecting either a single- or two-stage exchange arthroplasty. Other relevant variables such as the indication for primary hip arthroplasty or host type were poorly reported $(49.0 \%$ and $36.5 \%$ respectively). Other variables, such as age (90.7\%), gender (86.4\%), isolated pathogen (91.6\%), duration of interim period between stages $(88.6 \%)$, implant type used at exchange arthroplasty (72\%), length of antibiotic therapy (76.3\%), number of patients lost to follow-up $(73.8 \%)$ were more often reported.

\section{Recurrent infection}

\section{Single-stage vs two-stage}

We have analysed the data using a random-effects model to incorporate the wide range of variables.

The mean pooled proportion of recurrent infection was $12 \%(95 \% \mathrm{CI}=8 \%-17 \%)$ in single-stage hip exchange (1608 cases, $n=31$ studies) and demonstrated high clinical and methodological inconsistency between the studies included $\left(\mathrm{I}^{2}\right.$ value $\left.=80.3 \%, p<0.0001\right)$ (Fig. 2).

The mean pooled proportion of recurrence of infection was $9 \%$ (95\% CI = $8 \%-11 \%)$ in two-stage hip exchange (3679 cases, $n=74$ studies) and demonstrated moderate clinical and methodological inconsistency between the studies included $\left(\mathrm{I}^{2}\right.$ value $\left.=50.3 \%, p<0.0001\right)$ (Fig. 3).

The combined overlapped CIs from single- and twostage exchanges suggests similar effect between the interventions, as represented in Fig. 4. This estimate was confirmed by the comparisons of the available controlled studies $(n=15)$ : no statistically significant difference between people undertaking a single- versus a two-stage exchange in terms of recurrence of infection with a pooled odds ratio of $1.37\left(95 \% \mathrm{CI}=0.68-2.74, \mathrm{I}^{2}=45.5 \%, p=\right.$ 0.03) (Fig. 5).

\section{Single-stage cementless vs single-stage cemented}

The mean pooled proportion of infection recurrence in a single-stage hip cementless exchange (148 cases, $\mathrm{n}=6$ studies) was $14 \%$ (95\% CI $4 \%-28 \%)$, whereas in a cemented exchange (1271 cases, $n=19$ studies) it was $12 \%$ (95 \% CI 7 \%-17 \%). In both analyses a high clinical

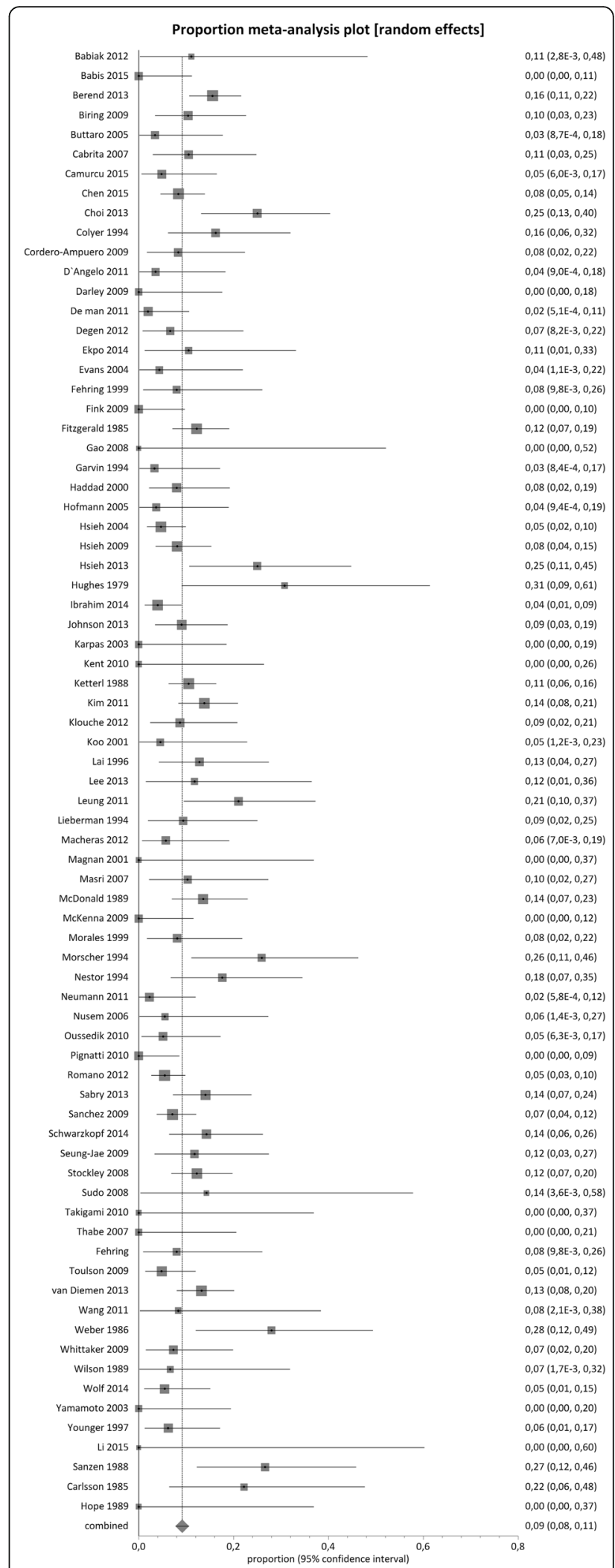

Fig. 3 Proportional meta-analysis regarding infection recurrence after two-stage hip arthroplasty 


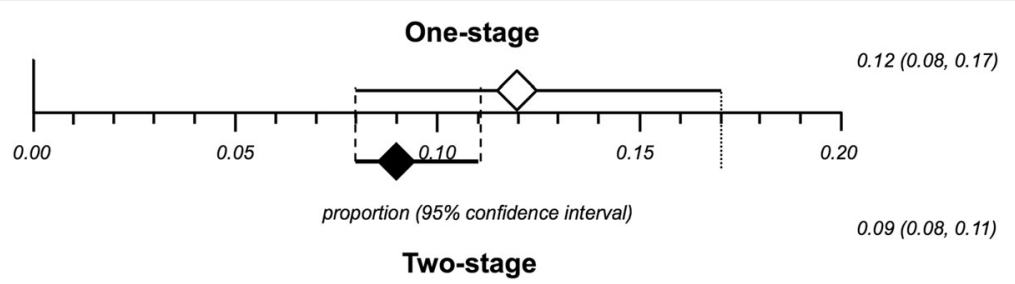

Fig. 4 Combined overlapped Cls from single- and two-stage exchange proportional meta-analyses

and methodological inconsistency was shown between the included studies $\left(\mathrm{I}^{2}\right.$ value $=77.4 \%$ for cementless and $\mathrm{I}^{2}$ value $=83.3 \%$ for cemented; $p<0.0001$ ).

Figures 6 and 7 present the pooled proportion for cementless and cemented hip exchanges. The combined overlapped $95 \%$ CIs from cementless and cemented single-stage exchanges suggests similar effect between the interventions studied, as represented in Fig. 8.

\section{Discussion}

This systematic review analyses the current published literature regarding a single- and two-staged exchange for hip periprosthetic infections, where the number of reported two-stage exchange arthroplasty studies largely exceeds that of a single-stage ones.

This study includes a much higher number of studies and patients compared to previous systematic reviews comparing both treatment options in a more limited population $[14,15]$ and is also, to our knowledge, the first attempt to investigate separately cemented and cementless one-stage revision procedures.

Our results failed to demonstrate a statistical difference between a single- and two-stage exchange arthroplasty, when applying a random effect model. Lange et al. [14] identified only a limited superiority of two-stage exchange arthroplasty in infection eradication, highlighting the low quality of available material, while Beswisk et al. [15] could not demonstrate any difference in eradication rates following a systematic review of studies with a minimum of 24 months of follow-up.

In line with these findings, when considering comparative studies only, the available material did not allow us to prove the superiority of single- or two-stage exchange arthroplasty, while a high heterogeneity of results was

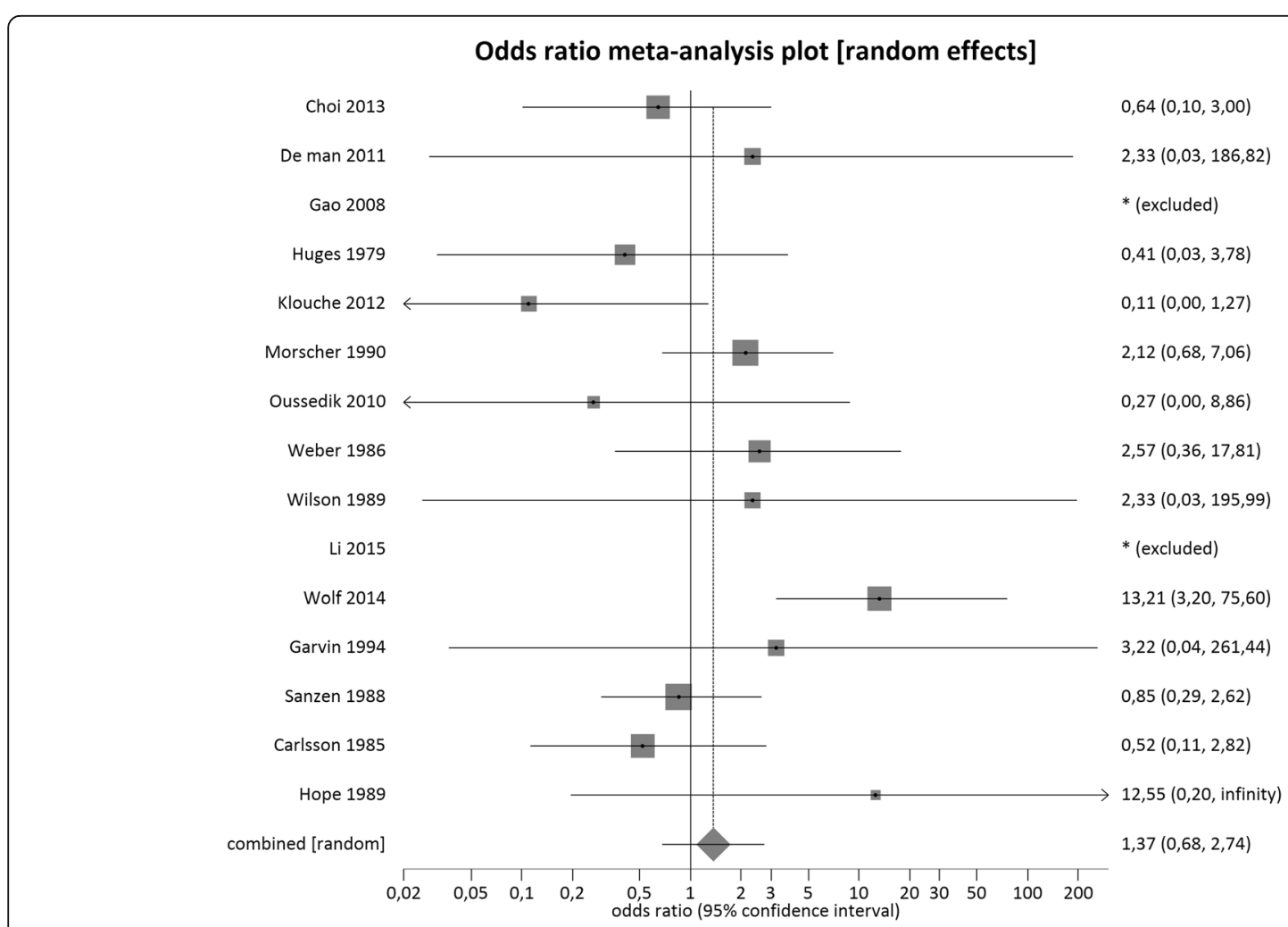

Fig. 5 Meta-analysis regarding infection recurrence after single-stage versus two-stage-exchange 


\section{Proportion meta-analysis plot [random effects]}

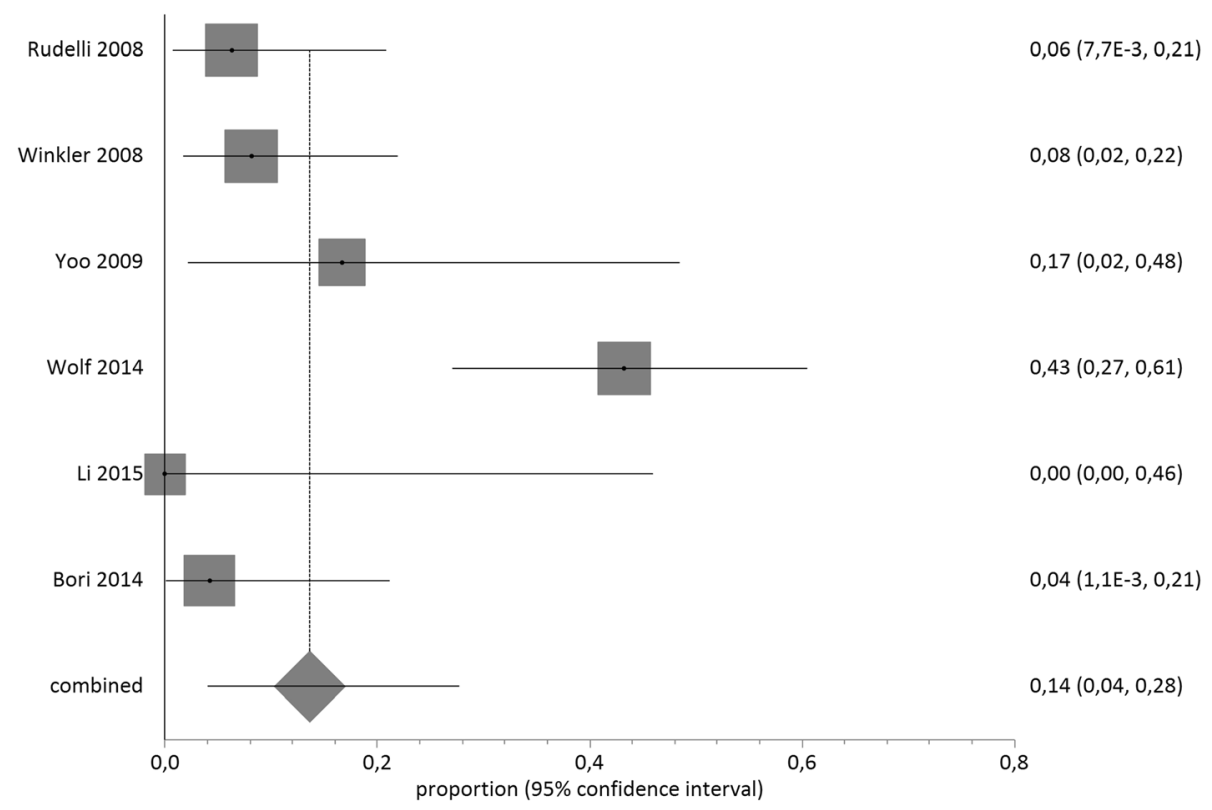

Fig. 6 Proportional meta-analysis regarding infection recurrence after cementless single-stage exchange

observed. As an example, Klouche and co-workers [22], recently reported no infection recurrence after single-stage exchange arthroplasty, even without using antibiotic-loaded cement, while Wolf et al. [23] demonstrated a $43 \%$ infection recurrence rate after singlestage exchange, compared to only $4 \%$ after two-stage revision. Further analysing their data, these authors provided evidence that the difference between the two treatments could be due to the better results obtained with a two-stage approach in more compromised hosts, while either seem to perform equally well, when normal hosts and early infections are involved [23].

Based upon the random-effects model used in our study, the rate of infection recurrence following a single-stage cementless exchange arthroplasty is not significantly different from single-stage cemented exchange. Once again, the limited number of studies and heterogeneity between both types, cemented and cementless, are worth considering.

More generally, the following limitations of the present study do apply. Patient selection and the eligibility for a single- or two-stage exchange arthroplasty may differ across centers; pathogen and host's type, implant model and degree of bone loss, type of hip spacer, use and dose of local antibiotics, time interval between stages, post-operative systemic antibiotic treatment, definition of infection, diagnosis and surveillance protocols are all important variables $[5,11$, 24-27] that were not reported uniformly across studies and were not considered in the present analysis.

A further limitation of this review concerns the study end-point, that we restricted to reporting infection recurrence, which limits the ability to catch differences in functional outcome, quality of life, or economical impact related to a given surgical option. In addition, we paid attention to the definition of measurements for recurrence of infection in order to investigate the "outcome reporting bias" but we were unable to distinguish between recurrent and new infections, as such a distinction was not made in the majority of the studies. The conventional definition of a 'new' infection is the isolation of a new microorganism, as opposed to the detection of the same pathogen in 'recurrent' infections, however we feel such a differentiation is unreliable. The microbiological results following periprosthetic samples are too unpredictable, especially after previous antibiotic treatment. The criteria for differentiating between recurrent and new infections is weakly supported in the literature, and somewhat artificial [16].

Classifing the design of included studies in order to judge their quality and internal validity was difficult. In fact, for an important part of studies the design assigned was unclear, and considering the inclusion of a paper or abstract published only in English we had an additional limit.

We found a substantial presence of the "record bias" for the majority of studies. Out of the 90 studies included, only 15 studies had a controlled group. The lack of a control group, and the prospective collection of data according to a protocol established before the beginning of the study, can affect the methodological quality limiting the external validity of findings.

We call for the need of large, multi-center randomised controlled trials with higher quality assessment in order to 


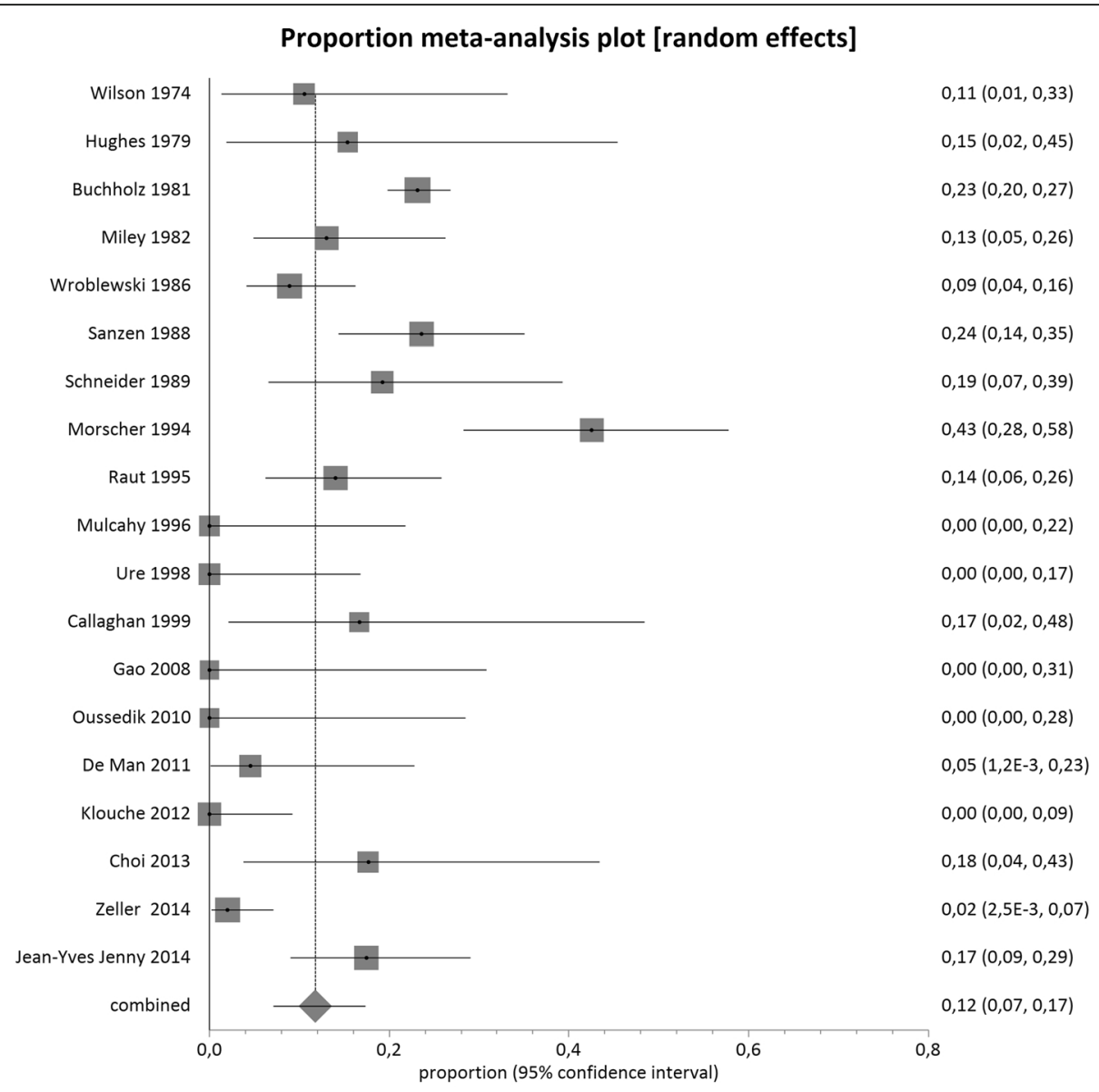

Fig. 7 Proportional meta-analysis regarding infection recurrence after cemented single-stage exchange

establish the superiority of one type of surgical treatment over another. However, certain circumstantial limitations such as the low incidence of the disease, relatively small patient cohorts, need for long-term follow-up, and variations in microorganisms and patients' co-morbidities, would also make a large controlled prospective study in this field extremely challenging.

\section{Conclusion}

No superiority was seen for a two-stage exchange arthroplasty over that of a single-stage for chronic periprosthetic hip infections, nor a statistical difference between cemented and cementless single-stage exchanges. This may reflect the shear complexity of this patient cohort and the difficulty in finding the true answer, and further reiterates that the ultimate choice of treatment modality depends on a variety of parameters not addressed in this review. This should include the patient's preoperative clinical status, potential benefits in function and quality of life to be gained from treatment, its economical implications, and complication rates.

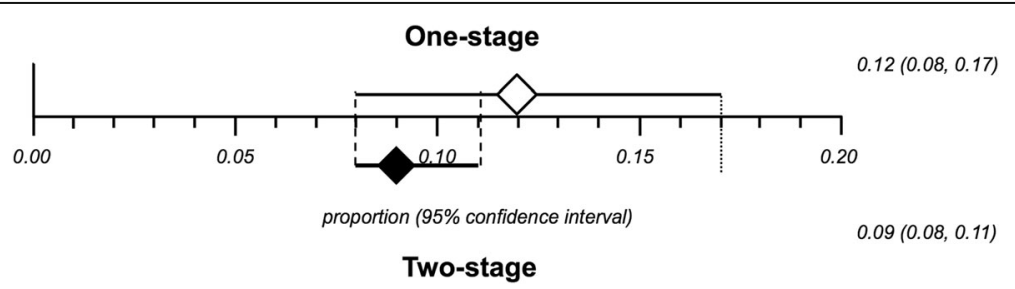

Fig. 8 Combined overlapped Cls from cementless and cemented single-stage exchange 


\section{Appendix 1}

Keywords entered either alone or in a variety of combinations during the systematic review process.

Hip Infection

Arthroplasty Prosthesis

Total hip replacement THR

Prosthetic hip infection Periprosthetic hip infection

Exchange arthroplasty One-stage

Single-stage Two-stagerevision

\section{Abbreviations}

$\mathrm{Cl}$ : Confidential intervals; n: number of patients; OR: Odds ratio

\section{Acknowledgements}

None.

\section{Funding}

The authors declare that there was no funding associated with the manuscript.

\section{Availability of data and materials}

All the data supporting our findings are contained within the manuscript.

\section{Authors' contributions}

DG: participated in the conception and design of the study, acquisition of data, interpreted the data, drafted the manuscript. NL: involved in the acquisition and interpretation of the data. GC and SG: participated in the acquisition of data, critically appraised and analysed the data, drafted the manuscript. SS and LD: involved in the acquisition and interpretation of the data. FSH: jointly conceived the study, participated in its design and interpreted the data. CLR: conceived the study, participated in its design, involved in the acquisition and interpreted of the data, drafted the manuscript and was overall coordinator. All authors read and approved the final manuscript.

\section{Competing interests}

The authors declare that they have no competing interests.

\section{Consent for publication}

Not applicable.

\section{Ethics approval and consent to participate}

No ethical approval was sought as it was deemed unneccesary for this meta-analysis.

\section{Author details \\ 'Department of Trauma and Orthopaedic Surgery, University College London Hospitals, London, UK. ${ }^{2}$ Centre for Reconstructive Surgery and Osteoarticular Infections, Orthopaedic Research Institute Galeazzi, Milan, Italy. ${ }^{3}$ Department of Biomedical Sciences for Health, University of Milan, Milan, Italy. ${ }^{4}$ RCCS Galeazzi Orthopaedic Institute, Unit of Clinical Epidemiology, Milan, Italy. ${ }^{5}$ Center of Biostatistics for Clinical Epidemiology, School of Medicine and Surgery, University of Milano-Bicocca, Monza, Italy. ${ }^{6}$ Clinical Chemistry and Microbiology Lab, IRCCS Galeazzi Institute, Milan, Italy.}

\section{Received: 7 June 2016 Accepted: 27 September 2016}

\section{Published online: 10 October 2016}

\section{References}

1. Bozic KJ, Kurtz SM, Lau E, Ong K, Vail TP, Berry DJ. The epidemiology of revision total hip arthroplasty in the United States. J Bone Joint Surg Am. 2009:91(1):128-33.

2. Phillips JE, Crane TP, Noy M, Elliott TSJ, Grimer RJ. The incidence of deep prosthetic infections in a specialist orthopaedic hospital, a 15-year prospective survey. J Bone Joint Surg (Br). 2006;88(7):943-8.

3. Berbari $E F$, Hanssen $A D$, Duffy MC, et al. Risk factors for prosthetic joint infection: case-control study. Clin Infect Dis. 1998;27:1247-54.

4. Willis-Owen CA, Konyves A, Martin DK. Factors affecting the incidence of infection in hip and knee replacement. An analysis of 5277 cases. J Bone Joint Surg (Br). 2010;92(8):1128-33.
5. Hart WJ, Jones RS. Two-stage revision of infected total knee replacements using articulating cement spacers and short-term antibiotic therapy. J Bone Joint Surg (Br). 2006;88(8):1011-5.

6. Kurd MF, Ghanem E, Steinbrecher J, Parvizi J. Two-stage exchange knee arthroplasty: does resistance of the infecting organism influence the outcome? Clin Orthop Relat Res. 2010;468(8):2060-6.

7. Parvizi J, Adeli B, Zmistowski B, Restrepo C, Greenwald AS. Management of periprosthetic joint infection: the current knowledge: AAOS exhibit selection. J Bone Joint Surg Am. 2012;94(14):e104.

8. Cabrita HB, Croci AT, Camargo OP, Lima AL. Prospective study of the treatment of infected hip arthroplasties with or without the use of an antibiotic-loaded cement spacer. Clinics. 2007;62(2):99-108.

9. Oussedik SI, Dodd MB, Haddad FS. Outcomes of revision total hip replacement for infection after grading according to a standard protocol. J Bone Joint Surg. 2010;92-B(9):1222-6.

10. Colyer RA, Capello WN. Surgical treatment of the infected hip implant. Twostage reimplantation with a one-month interval. Clin Orthop Relat Res. 1994 298:75-9.

11. Hsieh PH, Huang KC, Lee PC, Lee MS. Two-stage revision of infected hip arthroplasty using an antibiotic-loaded spacer: retrospective comparison between short-term and prolonged antibiotic therapy. J Antimicrob Chemother. 2009;64(2):392-7.

12. Choi HR, Kwon YM, Freiberg AA, Malchau H. Comparison of one-stage revision with antibiotic cement versus two-stage revision results for infected total hip arthroplasty. J Arthroplasty. 2013:28(8 Suppl):66-70.

13. Ketterl R, Henly MB, Stübinger B, Beckurts T, Claudi B. Analysis of three operative techniques for infected total hip replacements. Orthop Trans. 1988;12:715.

14. Lange J, Troelsen A, Thomsen RW, Søballe K. Chronic infections in hip arthroplasties: comparing risk of reinfection following one-stage and twostage revision: a systematic review and meta-analysis. Clin Epidemiol. 2012; 4(4):57-73.

15. Beswick AD, Elvers KT, Smith AJ, Gooberman-Hill R, Lovering A, Blom AW. What is the evidence base to guide surgical treatment of infected hip prostheses? Systematic review of longitudinal studies in unselected patients. BMC Med. 2012:10:18.

16. Romanò CL, Gala L, Logoluso N, Romanò D, Drago L. Two-stage revision of septic knee prosthesis with articulating knee spacers yields better infection eradication rate than one-stage or two-stage revision with static spacers. Knee Surg Sports Traumatol Arthrosc. 2012;20:2445-53.

17. George DA, Volpin A, Scarponi, Haddad FS, Romano CL. Does Revision Surgery Of Infected Shoulder Prosthesis Provide Better Eradication Rate And Better Functional Outcome, Compared To a Permanent Spacer or Resection Arthroplasty? A Systematic Review. BMC Musculoskelet Disord. 2016;17:52.

18. Der Simonian R, Laird N. Meta-analysis in clinical trials. Control Clin Trials. 1986;7:177-88.

19. Barretti P, Doles JV, Pinotti DG, El Dib R. Efficacy of antibiotic therapy for peritoneal dialysis-associated peritonitis: a proportional meta-analysis. BMC Infect Dis. 2014;14(1):445

20. El Dib R, Nascimento Junior P, Kapoor A. An alternative approach to deal with the absence of clinical trials: a proportional meta-analysis of case series studies. Acta Cir Bras. 2013;28(12):870-6.

21. Gurgel SJT, El Dib R, do Nascimento Jr P. Enhanced Recovery after Elective Open Surgical Repair of Abdominal Aortic Aneurysm: A Complementary Overview through a Pooled Analysis of Proportions from Case Series Studies. PLoS One. 2014;9(6):e98006.

22. Klouche $S$, Leonard $P$, Zeller $\mathrm{V}$, et al. Infected total hip arthroplasty revision: one- or two-stage procedure? Orthop Traumatol Surg Res. 2012;98(2):144-50.

23. Wroblewski BM. One-stage revision of infected cemented total hip arthroplasty. Clin Orthop Relat Res. 1986:211:103-7.

24. Hughes PW, Salvati EA, Wilson PD, Blumenfeld EL. Treatment of Subacute Sepsis of the Hip by Antibiotics and Joint Replacement Criteria For Diagnosis With Evaluation of Twenty-Six Cases. Clin Orthop Relat Res. 1979; 141:143-57.

25. Sudo A, Hasegawa M, Fukuda A, Uchida A. Treatment of infected hip arthroplasty with antibiotic-impregnated calcium hydroxyapatite. J Arthroplasty. 2008;23(1):145-50

26. Wilson MG, Dorr LD. Reimplantation of infected total hip arthroplasties in the absence of antibiotic cement. J Arthroplasty. 1989;4(3):263-9.

27. Winkler H, Stoiber A, Kaudela K, Winter F, Menschik F. One stage uncemented revision of infected total hip replacement using cancellous 
allograft bone impregnated with antibiotics. J Bone Joint Surg (Br). 2008; 90(12):1580-4.

28. Babiak I. Application of individually performed acrylic cement spacers containing $5 \%$ of antibiotic in two-stage revision of hip and knee prosthesis due to infection. Pol Orthop Traumatol. 2012;77:29-37.

29. Babis GC, Sakellariou VI, Pantos PG, Sasalos GG, Stavropoulos NA. Two-Stage Revision Protocol in Multidrug Resistant Periprosthetic Infection Following Total Hip Arthroplasty Using a Long Interval Between Stages. J Arthroplasty. 2015;30:1602-6.

30. Berend KR, Lombardi AV, Morris MJ, Bergeson AG, Adams JB, Sneller MA. Two-stage Treatment of Hip Periprosthetic Joint Infection Is Associated With a High Rate of Infection Control but High Mortality. Clin Orthop Relat Res. 2013:471:510-8.

31. Biring GS, Kostamo T, Garbuz DS, Masri BA, Duncan CP. Two-stage revision arthroplasty of the hip for infection using an interim articulated Prostalac hip spacer: a 10- to 15-year follow-up study. J Bone Joint Surg (Br). 2009; 91(11):1431-7.

32. Bori G, Muñoz-Mahamud E, Cuñé J, Gallart X, Fuster D, Soriano A. One-Stage Revision Arthroplasty Using Cementless Hip Arthroplasties. J Arthroplasty. 2014;29:1076-81.

33. Buchholz H, Elson R, Engelbrecht E, Lodenkamper H, Rottger J, Siegel A. Management of deep infection of total hip replacement. J Bone Joint Surg. 1981;63-B(3):342-53

34. Buttaro MA, Pusso R, Piccaluga F. Vancomycin-supplemented impacted bone allografts in infected hip arthroplasty. Two-stage revision results. $J$ Bone Joint Surg (Br). 2005;87:314-9.

35. Callaghan JJ, Katz RP, Johnston RC. One-stage revision surgery of the infected hip. A minimum 10-year followup study. Clin Orthop Relat Res. 1999;369:139-43.

36. Camurcu Y, Sofu H, Buyuk AF, Gursu S, Kaygusuz MA, Sahin V. Two-Stage Cementless Revision Total Hip Arthroplasty for Infected Primary Hip Arthroplasties. J Arthroplasty. 2015:30:1597-601.

37. Carlsson AS, Egund N, Gentz CF, Hussenius A, Josefsson G, Lindberg L. Radiographic loosening after revision with gentamicin-containing cement for deep infection in total hip arthroplasties. Clin Orthop Relat Res. 1985;194:271-9.

38. Chen SY, Hu CC, Chen CC, Chang YH, Hsieh PH. Two-Stage Revision Arthroplasty for Periprosthetic Hip Infection: Mean Follow-Up of Ten Years. Biomed Res Int. 2015;2015:345475.

39. Cordero-Ampuero J, Esteban J, Garcia-Cimbrelo E. Oral antibiotics are effective for highly resistant hip arthroplasty infections. Clin Orthop Relat Res. 2009;467(9):2335-42.

40. D'Angelo F, Negri L, Binda T, Zatti G, Cherubino P. The use of a preformed spacer in two-stage revision of infected hip arthroplasties. Musculoskelet Surg. 2011;95(2):115-20.

41. Darley E, Bannister G, Blom A, MacGowan AP, Jacobson S, Alfouzan W. Early intravenous to oral antibiotic switch therapy is effective in the treatment of infected total hip replacement. Clin Microbiol Infect. 2009;15(Suppl S4):S139.

42. De Man FH, Sendi P, Zimmerli W, Maurer TB, Ochsner PE, Ilchmann T. Infectiological, functional, and radiographic outcome after revision for prosthetic hip infection according to a strict algorithm. Acta Orthop. 2011;82(1):27-34.

43. Degen RM, Davey JR, Davey JR, Howard JL, McCalden RW, Naudie DD. Does a prefabricated gentamicin-impregnated, load-bearing spacer control periprosthetic hip infection? Clin Orthop Relat Res. 2012;470(10):2724-9.

44. Ekpo TE, Berend KR, Morris MJ, Adams JB, Lombardi Jr AV. Partial two-stage exchange for infected total hip arthroplasty: a preliminary report. Clin Orthop Relat Res. 2014;472(2):437-48.

45. Evans RP. Successful treatment of total hip and knee infection with articulating antibiotic components: a modified treatment method. Clin Orthop Relat Res. 2004:427:37-46.

46. Fehring TK, Calton TF, Griffin WL. Cementless fixation in 2-stage reimplantation for periprosthetic sepsis. J Arthroplasty. 1999;14(2):175-81.

47. Fink B, Grossmann A, Fuerst M, Schäfer P, Frommelt L. Two-stage cementless revision of infected hip endoprostheses. Clin Orthop Relat Res. 2009:467(7):1848-58.

48. Fitzgerald RH, Jones DR. Hip implant infection: Treatment with resection arthroplasty and late total hip arthroplasty. Am J Med. 1985;78(6):225-8.

49. Gao H, Lv H. One-stage revision operations for infection after hip arthroplasty. Zhongguo Xiu Fu Chong Jian Wai Ke Za Zhi. 2008;22(1):5-8.

50. Garvin KL, Evans BG, Salvati EA, Brause BD. Palacos gentamicin for the treatment of deep periprosthetic hip infections. Clin Orthop Relat Res. 1994; 298:97-105.
51. Haddad FS, Muirhead-Allwood SK, Manktelow AR, Bacarese-Hamilton I. Twostage uncemented revision hip arthroplasty for infection. J Bone Joint Surg (Br). 2000;82(5):689-94.

52. Hofmann AA, Goldberg TD, Tanner AM, Cook TM. Ten-year experience using an articulating antibiotic cement hip spacer for the treatment of chronically infected total hip. J Arthroplasty. 2005;20:874-9.

53. Hope PG, Kristinsson KG, Norman P, Elson RA. Deep infection of cemented total hip arthroplasties caused by coagulase-negative staphylococci. J Bone Joint Surg (Br). 1989;71(5):851-5.

54. Hsieh PH, Huang KC, Shih HN. Prosthetic joint infection in patients with rheumatoid arthritis: an outcome analysis compared with controls. PLoS One. 2013;8(8):e71666.

55. Hsieh PH, Shih $\mathrm{CH}$, Chang YH, Lee MS, Shih HN, Yang WE. Two-stage revision hip arthroplasty for infection: comparison between the interim use of antibiotic-loaded cement beads and a spacer prosthesis. J Bone Joint Surg Am. 2004;86-A(9):1989-97.

56. Ibrahim MS, Raja S, Khan MA, Haddad FS. A multidisciplinary team approach to two-stage revision for the infected hip replacement: a minimum five-year follow-up study. Bone Joint J. 2014;96-B:1312-8.

57. Ilchmann T, Zimmerli W, Ochsner PE, Kessler B, Zwicky L, Graber P, Clauss M. One-stage revision of infected hip arthroplasty: outcome of 39 consecutive hips. Int Orthop. 2016;40(5):913-8.

58. Jenny JY, Lengert R, Diesinger Y, Gaudias J, Boeri C, Kempf JF. Routine onestage exchange for chronic infection after total hip replacement. Int Orthop. 2014;38(12):2477-81.

59. Johnson AJ, Zywiel MG, Jones LC, Delanois RE, Stroh DA, Mont MA. Reduced re-infection rates with postoperative oral antibiotics after twostage revision hip arthroplasty. BMC Musculoskelet Disord. 2013;14(1):123.

60. Karpas K, Sponer P. Management of the infected hip arthroplasty by twostage reimplantation. Acta Med (Hradec Kralove). 2003;46(3):113-5.

61. Kent M, Rachha R, Sood M. A technique for the fabrication of a reinforced moulded articulating cement spacer in two-stage revision total hip arthroplasty. Int Orthop. 2010;34:949-53.

62. Koo KH, Yang JW, Cho SH, et al. Impregnation of vancomycin, gentamicin, and cefotaxime in a cement spacer for two-stage cementless reconstruction in infected total hip arthroplasty. J Arthroplasty. 2001:16:882-92.

63. Kim YH, Kim JS, Park JW, Joo JH. Cementless revision for infected total hip replacements. J Bone Joint Surg (Br). 2011:93(1):19-26.

64. Lai KA, Shen WJ, Yang CY, Lin RM, Lin CJ, Jou IM. Two-stage cementless revision THR after infection. 5 recurrences in 40 cases followed 2.5-7 years. Acta Orthop Scand. 1996;67(4):325-8.

65. Lee YK, Lee KH, Nho JH, Ha YC, Koo KH. Retaining well-fixed cementless stem in the treatment of infected hip arthroplasty. Acta Orthop. 2013;84(3):260-4.

66. Leung F, Richards CJ, Garbuz DS, Masri BA, Duncan CP. Two-stage total hip arthroplasty: how often does it control methicillin-resistant infection? Clin Orthop Relat Res. 2011;469(4):1009-15.

67. Li P, Hou M, Zhu ZQ, Shi ZJ. Cementless Revision for Infected Hip Arthroplasty: an 8.6 Years Follow-up. Orthop Surg. 2015;7(1):37-42.

68. Lieberman JR, Callaway GH, Salvati EA, Pellicci PM, Brause BD. Treatment of the infected total hip arthroplasty with a two-stage reimplantation protocol. Clin Orthop Relat Res. 1994;301:205-12.

69. Macheras GA, Koutsostathis SD, Kateros K, Papadakis S, Anastasopoulos P. A two stage re-implantation protocol for the treatment of deep periprosthetic hip infection. Mid to long-term results. Hip Int. 2012;22 Suppl 8:S54-61.

70. Magnan B, Regis D, Biscaglia R, Bartolozzi P. Preformed acnlic bone cement spacer loaded with antibiotics: use of two-stage procedure in 10 patients because of infected hips after total replacement. Acta Orthop Scand. 2001;72(6):591-4.

71. Masri BA, Panagiotopoulos KP, Greidanus NV, Garbuz DS, Duncan CP. Cementless two-stage exchange arthroplasty for infection after total hip arthroplasty. J Arthroplasty. 2007;22(1):72-8.

72. McDonald DJ, Fitzgerald RH, Ilstrup DM. Two-stage reconstruction of a total hip arthroplasty because of infection. J Bone Joint Surg. 1989;71-A(6):828-34.

73. McKenna PB, O'Shea K, Masterson EL. Two-stage revision of infected hip arthroplasty using a shortened post-operative course of antibiotics. Arch Orthop Trauma Surg. 2009;129(4):489-94.

74. Miley GB, Scheller AD, Turner RH. Medical and surgical treatment of the septic hip with one-stage revision arthroplasty. Clin Orthop Relat Res 1982; 170(76-82).

75. Morales FL, González JF, Ortiz FB, Martínez JM, Araujo CG. Treatment of infected hip arthroplasty. Retrospective study. Revista de Ortopedia y Traumatologia. 1999;43(2):84-92. 
76. Morscher E, Herzog R, Bapst R. Hip revision surgery in septic loosening. Chir Organi Mov. 1994;79(4):335-40.

77. Mulcahy DM, O'Byrne JM, Fenelon GE. One stage surgical management of deep infection of total hip arthroplasty. Ir J Med Sci. 1996;165(1):17-9.

78. Nestor BJ, Hanssen AD, Ferrer-Gonzalez R, Fitzgerald RH. The use of porous prostheses in delayed reconstruction of total hip replacements that have failed because of infection. J Bone Joint Surg Am. 1994;76:349-59.

79. Neumann DR, Hofstaedter T, List C, Dorn U. Two-Stage Cementless Revision of Late Total Hip Arthroplasty Infection Using a Premanufactured Spacer. J Arthroplasty. 2012;27(7):1397-401.

80. Nusem I, Morgan DA. Structural allografts for bone stock reconstruction in two- stage revision for infected total hip arthroplasty: good outcome in 16 of 18 patients followed for 5-14 years. Acta Orthop. 2006;77:92-7.

81. Pignatti $G$, Nitta $S$, Rani N, et al. Two stage hip revision in periprosthetic infection: results of 41 cases. Open Orthop J. 2010;4:193-200.

82. Raut W, Siney PD, Wroblewski BM. One-stage revision of infected total hip replacements with discharging sinuses. J Bone Joint Surg (Br). 1994;76(5):721-4.

83. Romanò $\mathrm{CL}$, Romanò $\mathrm{D}$, Albisetti $\mathrm{A}$, Meani E. Preformed antibiotic-loaded cement spacers for two-stage revision of infected total hip arthroplasty. Long-term results. Hip Int. 2012;22 Suppl 8:S46-53.

84. Rudelli S, Uip D, Honda E, Lima AL. One-stage revision of infected total hip arthroplasty with bone graft. J Arthroplasty. 2008;23(8):1165-77.

85. Sabry FY, Szubski CR, Stefancin JJ, Klika AK, Higuera CA, Barsoum WK. Comparison of complications associated with commercially available and custom-made articulating spacers in two-stage total hip arthroplasty revision. Curr Orthop Pract. 2013;24(4):406-13.

86. Sanchez-Sotelo J, Berry DJ, Hanssen AD, Cabanela ME. Midterm to longterm followup of staged reimplantation for infected hip arthroplasty. Clin Orthop Relat Res. 2009;467:219-24.

87. Sanzen L, Carlsson A, Josefsson G, Lindberg LT. Revision operations on infected total hip arthroplasties. Clin Orthop Relat Res. 1988;229:165-72.

88. Schneider R. The infected total prosthesis. Orthopade. 1989;18(6):527-32.

89. Schwarzkopf R, Mikhael B, Wright E, Estok DM, Katz JN. Treatment Failure Among Infected Periprosthetic Total Hip Arthroplasty Patients. Open Orthop J. 2014:8:118-24.

90. Lim S-J. Treatment of Periprosthetic Hip Infection Caused by Resistant Microorganisms Using 2-Stage Reimplantation Protocol. J Arthroplasty. 2009; 24(8):1264-9.

91. Stockley I, Mockford BJ, Hoad-Reddick A, Norman P. The use of two-stage exchange arthroplasty with depot antibiotics in the absence of long-term antibiotic therapy in infected total hip replacement. J Bone Joint Surg (Br). 2008:90:145-8

92. Takigami I, Ito $Y$, Ishimaru $D$, et al. Two-stage revision surgery for hip prosthesis infection using antibiotic-loaded porous hydroxyapatite blocks. Arch Orthop Trauma Surg. 2010;130(10):1221-6.

93. Thabe H, Schill S. Two-stage reimplantation with an application spacer and combined with delivery of antibiotics in the management of prosthetic joint infection. Oper Orthop Traumatol. 2007;19(1):78-100.

94. Toulson C, Walcott-Sapp S, Hur J, et al. Treatment of infected total hip arthroplasty with a 2-stage reimplantation protocol: update on "our institution's" experience from 1989 to 2003. J Arthroplasty. 2009;24(7):1051-60.

95. Ure KJ, Amstutz HC, Nasser S, Schmalzried TP. Direct-exchange arthroplasty for the treatment of infection after total hip replacement. An average tenyear follow-up. J Bone Joint Surg Am. 1998;80:961-8.

96. van Diemen MP, Colen S, Dalemans AA, Stuyck J, Mulier M. Two-stage revision of an infected total hip arthroplasty: a follow-up of 136 patients. Hip Int. 2013;23(5):445-50.

97. Wang L, Hu Y, Dai Z, Zhou J, Li M, Li K. Mid-term effectiveness of two-stage hip prosthesis revision in treatment of infection after hip arthroplasty. Zhongguo Xiu Fu Chong Jian Wai Ke Za Zhi. 2011;25(6):646-9.

98. Weber FA, Lautenbach EEG. Revision of infected total hip arthroplasty. Clin Orthop Relat Res. 1986;211:108-15.

99. Whittaker JP, Warren RE, Jones RS, Gregson PA. Is prolonged systemic antibiotic treatment essential in two-stage revision hip replacement for chronic Gram-positive infection? J Bone Joint Surg (Br). 2009;91(1):44-51.

100. Wilson PD, Aglietti P, Salvati EA. Subacute sepsis of the hip treated by antibiotics and cemented prosthesis. J Bone Joint Surg. 1974;56-A(5):879-98.

101. Wolf M, Clar H, Friesenbichler J, et al. Prosthetic joint infection following total hip replacement: results of one-stage versus two-stage exchange. Int Orthop. 2014;38(7):1363-8.
102. Yamamoto K, Miyagawa N, Masaoka T, Katori Y, Shishido T, Imakiire A. Clinical effectiveness of antibiotic-impregnated cement spacers for the treatment of infected implants of the hip joint. J Orthop Sci. 2003;8(6):823-8.

103. Yoo JJ, Kwon YS, Koo KH, Yoon KS, Kim YM, Kim HJ. One-stage cementless revision arthroplasty for infected hip replacements. Int Orthop. 2009;33(5): 1195-201.

104. Younger AS, Duncan CP, Masri BA, McGraw RW. The outcome of two-stage arthroplasty using a custom-made interval spacer to treat the infected hip. J Arthroplasty. 1997;12(6):615-23.

105. Zeller V, Lhotellier L, Marmor S, et al. One-stage exchange arthroplasty for chronic periprosthetic hip infection: results of a large prospective cohort study. J Bone Joint Surg Am. 2014;96(1):e1.

\section{Submit your next manuscript to BioMed Central and we will help you at every step:}

- We accept pre-submission inquiries

- Our selector tool helps you to find the most relevant journal

- We provide round the clock customer support

- Convenient online submission

- Thorough peer review

- Inclusion in PubMed and all major indexing services

- Maximum visibility for your research

Submit your manuscript at www.biomedcentral.com/submit
) Biomed Central 